\title{
Quality of Life of Colorectal Cancer Patients with Intestinal Stomas
}

\author{
Cristilene Akiko Kimura $^{1 *}$, Ivone Kamada ${ }^{2}$, Cristine Alves Costa de Jesus ${ }^{2}$ and Dirce Guilhem ${ }^{3}$ \\ ${ }^{1}$ Masters in Nursing, Attorney, Sena Aires College and Faculty of Health Sciences and Education (FACESA), Valparaíso de Goias, Brazil \\ ${ }^{2}$ Department of Nursing, College of Health Sciences, University of Brasilia, Brazil \\ ${ }^{3}$ Department of Nursing, College of Health Sciences, University of Brasilia, Brazil
}

*Corresponding author: Cristilene Akiko Kimura, SQNW Quadra 311, Edifício Montparnasse, BL B, Apto 116, Setor Noroeste, Brasília-Distrito Federal, Brasil, Tel: +55 (61) 8139 5839; E-mail: cris.akiko7@gmail.com

Rec date: Jun 17, 2014; Acc date: Aug 27, 2014; Pub date: Sep 02, 2014

Copyright: ( 2014 Kimura CA, et al. This is an open-access article distributed under the terms of the Creative Commons Attribution License, which permits unrestricted use, distribution, and reproduction in any medium, provided the original author and source are credited.

\begin{abstract}
This descriptive, cross-sectional, epidemiological study set out to analyze the association between domains and facets of quality of life among colorectal cancer patients attending the Outpatient Care Program for Patients with Stomas run by the Health Department of the Federal District, in Brazil. It was used a non-probability sampling with the inclusion of 120 participants during the period from November 2009 to August 2011. Statistical analysis used version 20.0 of the SPSS Software as recommended by the World Health Organization. Statistical significance adopted was p-value <0.05. Quality of Life was assessed using the WHOQOL-bref questionnaire. The facets of the Physical, Social Relations and Environmental domains showed statistically significant $(p<0.0001)$ correlation with the average scores. In the Psychological Domain, only the facet "positive feelings" was not statistically significant. The study pointed out that the creation of an intestinal stoma as part of neoplasm treatment leads to significant changes in the physical body and suffering associated to the newly imposed lifestyle, affecting physical and psychological aspects as well as social relations and the individuals' environment, thereby jeopardizing their quality of life in various dimensions. This knowledge is important insofar as it can contribute to the elaboration of holistic public policies, to the reorganization of care practices provided to health service users, and to the construction of education programs promoting health and rehabilitation specifically directed at meeting the real needs of this group.
\end{abstract}

Keywords: Quality of life; Colorectal neoplasms; Surgical stomas.

\section{Introduction}

The World Health Organization defines Quality of Life as individuals' perception of their position in life in the context of the culture and value systems in which they live and in relation to their goals, expectations, standards and concerns [1]. Quality of life is a subjective concept that implies personal satisfaction with various aspects, especially those considered essential to the individual's life. Maintaining physical integrity of the body is highly important, so far as it gives a sense of personal well-being and of being in harmony with the social context [2]. Any breach of that physical integrity such as an intestinal stoma created in colorectal cancer treatment can introduce serious physical, psychological and social problems [2].

Colorectal cancer is among the commonest reasons for carrying out intestinal ostomy. Among the risk factors associated to this type of cancer there is a proven link with nutritional patterns consisting of inadequate dietary habits and vices. The consumption of animal fats and red meat, and diets poor in fibers, fruits vegetables or cereals foster bacterial development leading to the degradation of bile acids and production of carcinogens [3,4]. It is the second most prevalent type of cancer in the world; third in incidence rates among men and second among women. It is therefore considered one of the most important neoplasms affecting adult populations and in most countries' incidence and mortality from it are on the increase [4-7].

When people fall ill with colorectal cancer, there are two important cultural implications: cancer as a disease, which carries the stigma of death and suffering; and the surgical opening of an intestinal stoma, a physical mutilation that, in spite of being hidden, has consequences that seriously interfere with people's daily lives [4-8]. For individuals with an intestinal stoma, the alteration to their physical bodies and the suffering due to the new style of life implicit in the use of the collecting equipment jeopardize their social performance and their interpersonal relations.

With the self-image of their own bodies altered and their selfesteem at a low ebb, persons with stomas tend to withdraw and isolate themselves socially, further hampering their quality of life and that, in turn, has physical, psychological and social consequences for them and their environments [9-11].

It is therefore necessary to investigate people's perceptions of how these aspects affect their lives. There are several instruments available for measuring quality of life and among the most widely used are the World Health Organization Quality of Life - 100 (WHOQOL-100) and its shortened version, WHOQOL-bref [12]. The latter instrument adopts a multi-cultural approach and addresses three important aspects, namely, subjectivity (individuals' perceptions of their own lives), multi-dimensionality (embracing various dimensions of life), and the presence of elements of evaluation (both positive and negative) $[1,12]$. The instrument addresses four domains (physical, psychological, social relations and environmental) each of which is sub-divided into items or facets [12].

This study set out to analyze possible associations among the facets and the respective domains of quality of life among colorectal cancer patients with intestinal stoma participating in the Outpatient Care Program for Patents with Stomas run by the Health Department of the Federal District, in Brazil 
Citation: Kimura CA, Kamada I, de Jesus CAC, Guilhem D (2014) Quality of Life of Colorectal Cancer Patients with Intestinal Stomas . J Carcinog Mutagen S10: 007. doi:10.4172/2157-2518.S10-007

Page 2 of 7

\section{Materials and Methods}

\section{Study methodology}

This descriptive, cross-sectional, epidemiological study analyzed data obtained from a sample group of colorectal cancer patients that have undergone ostomies. Observation and measurement of the variables of interest were made simultaneously thereby constituting a statistical portrait of the situation at a given moment.

The Research Ethics Committee of the Secretary of Health from the Federal District Government, Brazil, was responsible for the review and approval of the research protocol, under registration number $418 / 200$. The persons that agreed to participate signed an Informed Consent Form after receive detailed information related to objectives, procedures and participants' rights for their inclusion in the study. The participants receive the guarantee of privacy, confidentiality and anonymity's preservation according the requirements of the Brazilian regulatory norms governing research involving human beings [13].

\section{Sampling}

It was used a non-probability sampling technique: during the period from November 2009 through August 2011, all patients with intestinal stomas registered in the Outpatient Care Program for patients with Stomas offered by the Health Department of the Federal District, in Brazil, were invited to participate in the study. Those who agreed to participate spontaneously were included in the study. The final sample included 120 participants.

The inclusion criteria were a previous diagnosis of colorectal cancer, surgical intervention for the confection of an intestinal stoma and being aged twenty or above. The exclusion criteria were to be children, adolescents, pregnant women, lactating women, bed-ridden individuals, and people with other physical or intellectual handicaps.

\section{Data collection}

For data collection, performed from November 2009 to August 2011, it was making use of two instruments: a socio-demographic and clinical questionnaire and the validated Portuguese-language version of the WHOQOL-bref instrument. It is an abbreviated version of the instrument for Quality of Life's evaluation (WHOQOL-100), developed by the World Health Organization. The Brazilian Portuguese version validated in 1998 - considering semantic and cultural aspects -, was performed by the Department of Psychiatry and Forensic Medicine at the Federal University of Rio Grande do Sul $[12,14]$. Since then, the questionnaire is a reference for the quality of life's evaluation used in used in many studies for different population groups in the country.

The questionnaire include 26 items: two questions formulated in general terms and inquire into peoples' perceptions of their quality of life and satisfaction with their state of health. The four domains (physical, psychological, social relations and environment) and their respective facets, have objective and subjective items presented for evaluation. Answers are delivered in the form of a rating on a Likerttype scale with values ranging from 1 to 5 . The ranges correspond to: nothing - extremely, for intensity; nothing - completely, for capacity; never - always, for frequency; and highly dissatisfied - highly satisfied, or very bad - very good, for assessment $[12,14]$.

\section{Statistical analysis}

A descriptive statistical analysis was made of the data obtained from socio-demographic and clinical questionnaire. The data from the WHOQOL-bref questionnaire were analyzed by calculating average values, standard deviations, and proportions and inferential analysis made use of the following statistical procedures: confidence interval 95\%, t-student test with normal distribution, the Mann-Whitney test without normal distribution and the Pearson's correlation coefficient.

In accordance with World Health Organization recommendations, version 20.0 of the SPSS Software (Statistical Package of the Social Sciences, SPSS Inc., Chicago, USA) for Windows was used to conduct the statistical analysis. Statistical significance was set at $\mathrm{p}$-values $<0.05$.

\section{Results}

Table 1 presents the socio-demographic characteristics of the study participants. It can be seen that average age was $58.72 \pm 12.56$ with most of the participants being in the 50 to 69 age group $(n=66)$. The female sex was slightly predominant corresponding to $53.3 \%$ of participants $(\mathrm{n}=64)$.

In terms of religion, Catholicism was predominant, $56.7 \%(\mathrm{n}=68)$, followed by the Evangelical cults, 30.9\% ( $n=37)$; and $77.5 \%(n=93)$ of participants declared that they practiced some form of religion while $22.5 \%(n=27)$ stated that they belonged to no religious group.

For the marital status there was a predominance of married individuals $(62.5 \% ; \mathrm{n}=75)$, and most of the sample group declared that they lived in a family environment $(93.3 \% ; \mathrm{n}=112)$. In relation of formal education, $46.7 \% \quad(n=56)$ had completed lower secondary education (nine years of obligatory schooling). Regarding the employment, most of the group (65.8\%; $n=79)$ were retired. Declared monthly familiar incomes were in the range of 1 to 3 minimum salaries $(74.2 \% ; \mathrm{n}=89)$ with the minimum salary at the time of the study corresponding to $\mathrm{R} \$ 622.00$ (six hundred and twenty-two Brazilian reals).

\begin{tabular}{|c|c|c|}
\hline \multirow[t]{2}{*}{ Variables } & \multicolumn{2}{|c|}{ Individuals with intestinal stoma due to CRC } \\
\hline & $N=120$ & $\%$ \\
\hline \multicolumn{3}{|l|}{ SEX } \\
\hline Female & 64 & 53.3 \\
\hline Male & 56 & 46.7 \\
\hline \multicolumn{3}{|c|}{ AGE GROUP } \\
\hline $20-29$ & 9 & 7.5 \\
\hline $30-39$ & 18 & 15 \\
\hline $40-49$ & 31 & 25.8 \\
\hline $50-59$ & 35 & 29.2 \\
\hline $60-69$ & 25 & 20.9 \\
\hline $80-89$ & 2 & 1.6 \\
\hline \multicolumn{3}{|l|}{ RELIGION } \\
\hline Catholic & 68 & 56.7 \\
\hline Evangelical & 37 & 30.9 \\
\hline
\end{tabular}


Citation: Kimura CA, Kamada I, de Jesus CAC, Guilhem D (2014) Quality of Life of Colorectal Cancer Patients with Intestinal Stomas . J Carcinog Mutagen S10: 007. doi:10.4172/2157-2518.S10-007

Page 3 of 7

\begin{tabular}{|l|l|l|}
\hline Spiritualist & 11 & 9.1 \\
\hline Others & 4 & 3.3 \\
\hline \multicolumn{2}{|l|}{ PRACTICE RELIGION } & \multicolumn{2}{l|}{} \\
\hline Yes & 93 & 77.5 \\
\hline No & 27 & 22.5 \\
\hline MARITAL STATE & \multicolumn{2}{l|}{} \\
\hline Married & 75 & 62.5 \\
\hline Stable Union & 13 & 10.8 \\
\hline Divorced & 17 & 14.2 \\
\hline Widowed & 12 & 10 \\
\hline Single & 3 & 2.5 \\
\hline FAMILYLIEE &
\end{tabular}

\section{FAMILY LIFE}

\begin{tabular}{|l|l|l|}
\hline With family life & 112 & 93.3 \\
\hline No family life & 8 & 6.7 \\
\hline
\end{tabular}

\section{SCHOOLING}

\begin{tabular}{|l|l|l|}
\hline $\begin{array}{l}\text { None to Lower } \\
\text { Secondary }\end{array}$ & 56 & 46.7 \\
\hline $\begin{array}{l}\text { Higher Secondary } \\
\text { Education }\end{array}$ & 45 & 37.5 \\
\hline Higher Education & 19 & 15.8 \\
\hline
\end{tabular}

\section{LABOR MARKET STATUS}

\begin{tabular}{|l|l|l|}
\hline Retired & 79 & 65.8 \\
\hline Laid Off & 21 & 17.5 \\
\hline Working & 11 & 9.2 \\
\hline Unemployed & 9 & 7.5 \\
\hline INCOME & 89 & 74.2 \\
\hline$<1$ to 3 MS & 18 & 15 \\
\hline 4 to 5 MS & 13 & 10.8 \\
\hline$>6$ MS & \multicolumn{2}{|l|}{} \\
\hline
\end{tabular}

Table 1: Sample of colorectal cancer patients with stomas, by sociodemographic characteristics. Brasilia, Federal District, Brazil, 2011.

Table 2 points out the clinical profile of the participants. The variable "time elapsed since stoma implantation" showed that the largest number $46.7 \%(n=56)$ was in the group of $>60$ months followed by those in the group of $>12$ months and $\leq 60$ months (33.3\%; $n=40$ ). About the nature of the intestinal stoma, $67.5 \%(\mathrm{n}=81)$ had definitive stomas and $94.1 \%(n=113)$ did not use the irrigation system. For the variable co-morbidity, it was found that $56.7 \%(n=68)$ had high blood pressure and $34.1 \%(n=41)$ had Diabetes Mellitus. Furthermore, $43.3 \%$ $(n=52)$ of the respondents were smokers.

Table 3 demonstrates that people with intestinal stomas presented significant level of association among most of the facets included in the Physical domain. The most outstanding degree of correlation was found among the facets activities of daily life, work capacity, sleep and rest, and pain and discomfort. In the domain of Social Relations, indicated in Table 5, it can be seen that three facets are correlated to a statistically significant range $(\mathrm{p}<0.001)$ to the average score for the domain, namely, social relations, sexual activity and social support.

The results for the Environment domain showed weaker correlation values than those obtained for the other domains. Only two facets stood out as having a correlation with the average score obtained for the domain: health care and social care (availability and quality, and the opportunity to acquire new information and skills).

\section{Discussion}

The analysis of the socio-demographic and clinical data revealed an average age for the group of $58.72 \pm 12.56$ and that is comparable to the data obtained by other studies which indicate a prevalence of colorectal cancer in persons with 50 years or more, reaching $90 \%$ of the cases $[4,5]$.

\begin{tabular}{|l|l|l|}
\hline Variables & N=120 & $\%$ \\
\hline \multicolumn{2}{|l|}{ Time Elapsed Since Stoma Implantation (in months) } \\
\hline$\leq 12$ months & 24 & 20 \\
\hline$>12$ months and $\leq 60$ months & 40 & 33.3 \\
\hline$>60$ months & 56 & 46.7 \\
\hline Nature Of Intestinal Stoma & \multicolumn{2}{|l|}{} \\
\hline Definitive & 81 & 67.5 \\
\hline Temporary & 39 & 32.5 \\
\hline Irrigation System Use & \multicolumn{2}{|l|}{} \\
\hline Yes & 7 & 5.9 \\
\hline Diabetes Mellitus & \multicolumn{2}{|l|}{} \\
\hline Yes & 41 & 34.1 \\
\hline Hypertension & 68 & 56.7 \\
\hline Yes & 52 & 43.3 \\
\hline Smoking & \multicolumn{2}{|l|}{} \\
\hline Yes & & \\
\hline
\end{tabular}

Table 2: Sample group of patients with intestinal stoma due to colorectal cancer, by clinical characteristics, Brasilia, Federal District, Brazil, 2011.

The results show the predominance of females which is in alignment with the findings of the Brazilian National Cancer Institute (INCA is the Portuguese acronym) study for the year 2012, considered equally valid for the year 2013. The Institute's report totalized 14,180 new cases of colorectal cancer among men and 15,960 among women. Estimates for the numbers of new cases of colorectal cancer in the Federal District are 510, of which 220 are in men and 290 in women [15].

The predominant religion was Catholicism 56.7\% ( $\mathrm{n}=68)$, followed by Evangelical cults thus reflecting the situation in Brazil, considered to be the largest Catholic country in the world. Religious practices in 
the presence of an infirmity of this nature can offer an opportunity for spiritual growth insofar as the condition reminds the individual of the fragility of life and the nearness of human finitude. Spiritual well-being is not only associated to the physical and psychological dimensions but also, to the cultural background in which the individual finds himself inserted [16].

For the variable marital status, most of the patients, $62.5 \%(n=75)$, were married and $10.8 \%(n=13)$ were in some form of stable union. International studies that include people with colorectal neoplasms pointed out that $60 \%$ of them were married and that $95 \%$ lived with a partner $[17,18]$. Brazilian studies have also registered this association indicating that most of the individuals with stomas are married with percentages rates from $61.9 \%$ to $87.5 \%$ of those surveyed $[4,5,19]$. This is important information because, irrespective of the kind of conjugal arrangement, being married constitutes a protective factor considering that married people have higher levels of physical and psychological well-being than single, separated or divorced individuals [20,21].

Most of the participants, $93.3 \%(n=112)$, declared that they lived with family. It is an important source of support for the person with a stoma especially in the aspect of the physical attention, care and affection that the family provides. Often the circle is expanded to include people belonging to the sphere of the patient's social relations who offer their support in the process of facing up to the new health conditions imposed by the illness [4,5].

Regarding the formal education levels and family income, the group was largely constituted by people with low levels of formal education with $46.7 \% \quad(n=56)$ not having gone beyond, or having failed to complete mandatory (primary and lower secondary) education. This fact restricted their labor market possibilities, reflecting in low family incomes (around 2.25 official minimum salaries/month). This situation highlights the relevance of government assistance measures for this clientele and such backgrounds may be a factor jeopardizing colorectal cancer prevention. Poor information regarding predisposing factors to the disease results in diets with low levels of consumption of fresh fruits, vegetables, cereals and fish, as well as little physical exercise [4,5]. Educational levels also influence people's quality of life insofar as higher schooling levels generally have a positive influence on it [4], and economic problems associated to lower educational levels may have a negative effect [10].

The labor market status revealed a predominance of retired individuals: $65.8 \%(\mathrm{n}=79)$, of which $17.5 \%(\mathrm{n}=21)$ discharged for disability reasons pointe out by the Brazilian Social Security System. The highest proportion of retired individuals was among those with definitive stomas provided for a specific legislation, Decree No 5.296 dated from December 02, 2004, that classifies this group as persons with disabilities [4].

Regarding the kind of intestinal stoma, definitive stomas were preeminent reaching $67.5 \%(\mathrm{n}=81)$ among participants. The surgery to construct an intestinal stoma as a result of colorectal cancer requires a series of adaptations due to the modifications it imposes on various physical, psychological, social and environmental aspects of people's daily lives, jeopardizing their quality of life, regardless of whether the stoma is temporary or definitive $[5,8,10]$.

In the case of co-morbidities, $34.1 \%(n=41)$ of the individuals had type II diabetes and it constitutes an important risk factor for colorectal cancer considering that hyperinsulinemia that typifies the early stages of this particular neoplasm. The condition arises because the insulin plays the role of a growth factor for the colonic mucosa level, inhibiting apoptosis, and does so by increasing the synthesis of IGF-1 receptors [22,23]. Associated with this, 56.7\% $(n=68)$ of the participants declared they were hypertensive. The association of the two health conditions contributed to the patients' high propensity for developing colorectal cancer.

Besides that, $43.3 \%(n=52)$ of interviewed affirmed to be smokers. It is true that the colon is not directly affected by the composition of tobacco, but carcinogens carried by the blood can have a negative impact and enhance the risk of developing colorectal cancer. Furthermore, the number of packs per year and the duration of the smoking habit contribute to the development of adenomas and consequently increase the risk of colorectal cancer [24].

Although the study only observed a small group of people using irrigation $(5.9 \% ; n=7)$, the procedure offers advantages and health workers should make it well known to this clientele. Irrigation has no side effects, makes intestinal control feasible and benefits social and family relations thereby enhancing the quality of life of people with stomas [9]. It also helps to periodically reduce the bacterial flora in the colon contributing to a reduction in the formation of gases $[9,25]$.

Regarding to the WHOQOL-bref questionnaire results, we decide to describe only those facets that presented higher degree of association ( $r>0.71)$, that is, those that represent a strong correlation with their respective domains.

\begin{tabular}{|l|l|l|l|}
\hline $\begin{array}{l}\text { Item of the } \\
\text { Question. }\end{array}$ & Facet evaluated & $\mathbf{r}$ & $\mathbf{p}$ \\
\hline 1 & Pain and discomfort & -0.72 & $<0.0001$ \\
\hline 2 & Energy and fatigue & 0.54 & $<0.0001$ \\
\hline 3 & Sleep and rest & -0.74 & $<0.0001$ \\
\hline 9 & Mobility & -0.66 & $<0.0001$ \\
\hline 10 & Activities of daily life & -0.78 & $<0.0001$ \\
\hline 11 & $\begin{array}{l}\text { Medication } \\
\text { dependency }\end{array}$ & -0.50 & $<0.0001$ \\
\hline 12 & Work capacity treatment & -0.75 & $<0.0001$ \\
\hline
\end{tabular}

Table 3: Correlation of each question of the questionnaire to the average score for the Physical Domain. Participant's with intestinal stoma due to colorectal cancer. Brasília, Federal District, Brazil, 2011.

Table 3 points outs that facets activities of daily life, work capacity, sleep and rest, belonging to the Physical domain, are higher correlated to the average score of individuals with stomas by reason of colorectal cancer, leading to a worsened perception of quality of life in that domain. The wish to undertake normal daily activities is usual among cancer patients with stomas, but it runs contrary to another feeling of limitation or loss of the capacity to work and make a useful contribution to society that leaves them dispirited when they find it hard to get into the labor market $[4,26]$. Work activities contribute to structuring important meanings in the life of the individual and to strengthening health conditions for physical wellbeing. Work enhances an individual's value as a person fully integrated to society. It is necessary to make the situation of such persons more widely known and to conduct studies designed to explore their work possibilities so that healthy workers and society can seek to identify spaces where they can contribute in the labor market thereby improving their social mobilization. 
Among the interviewed, the facet pain and discomfort was the one showing the highest degree of correlation in the context of the Physical domain. This result can be compared those to reported by other studies that identified the presence of pain and discomfort as having a negative effect on perceptions of quality of life. Pain, self-image of the body, sexual activity and social anxiety were the aspects most affected, but pain is great and recurrent among cancer patients [4,19,27]. In addition to pain, the question of sleep and rest, reduced mobility and difficulty in performing the activities of daily life as well as capacity for work are in intimate relation to the reduction of the quality of life regarding to the physical performance of cancer patients with intestinal stomas [2].

Concerning the facet sleep and rest in particular, the study detected a strong negative correlation with the quality of life of the respondents. A similar result was obtained by a study describing the interruption of sleep patterns in stoma patients showing a correlation with the scale of physical capacity. The quality of sleep has direct influence on the individuals' routines; insufficient sleep can have negative impacts on health impeding the renewal of energy spent in daily work and heightening feelings of weariness and mental and bodily fatigue [10].

In the Psychological domain, the results set out in Table 4 show that spirituality, religion and personal beliefs were the facets most strongly associated to the average quality of life score in this domain. Religiosity can have a positive influence for patients facing illness and the presence of an intestinal stoma, and improve his or her quality of life in the psychological sphere [19]. Religion is considered to be an important tool in the construction of human beings' personalities, an expression of their identity and purpose in the light of their histories, experiences and aspirations [28,29]. There have been scientific investigations clearly demonstrating that people with a strong degree of religiosity tend to have shorter hospital stays $[4,5,9]$.

\begin{tabular}{|l|l|l|l|}
\hline $\begin{array}{l}\text { Item of the } \\
\text { Questionnair } \\
\text { e }\end{array}$ & Facet Evaluated & $\mathbf{r}$ & $\mathbf{p}$ \\
\hline 4 & Positive feelings & 0.39 & 0.293 \\
\hline 5 & $\begin{array}{l}\text { Thinking, learning, memory and } \\
\text { concentration }\end{array}$ & 0.41 & 0.459 \\
\hline 6 & Self-esteem & -0.72 & $<0.0001$ \\
\hline 7 & Body image and appearance & -0.73 & $<0.0001$ \\
\hline 8 & Negative feelings & -0.55 & $<0.0001$ \\
\hline 24 & Spirituality/religion/personal beliefs & 0.80 & $<0.0001$ \\
\hline
\end{tabular}

Table 4: Correlation of each question of the questionnaire to the average score for the Psychological Domain. Participants with intestinal stoma due to colorectal cancer. Brasília, Federal District, Brazil, 2011.

Religious faith is orientated towards something superior, supernatural and all-powerful. Thus spirituality, religion and personal beliefs are capable of relieving suffering because they make it possible to alter subjective representations in the light of the disease, to permit personal growth by stimulating a reflection on life, on how it has been lived and on the individual's finitude [30].

Still in the psychological domain, the aspects of body image and appearance as well as self-esteem can have a negative effect on the perceptions of quality of life. The impact cause by a presence of a stoma implies in the body's alteration what is no longer in compliance with the social standards. It interferes in the intra-psychic sphere and the self-image of the body is transformed having as consequence various negative reactions and reduces self-esteem as well fostering a perception of loss of life on the part of the cancer patient with a stoma $[2,4,29]$. The body image is one of the fundamental components of identification. Any alteration arising from a bodily mutilation (intestinal stoma) confronts the person with the representation an ideal body - based on concepts of harmony, beauty and health -, and may lead people to feel aversion to their own bodies [29].

Alterations in the self-image of the body may conduct to psychological alterations as lower levels of self-esteem, negative feelings, anxieties and fears associated to the struggle to satisfy desires and overriding concern as to how to handle the problems stemming from deceptions in daily life [10]. The body image is such an important aspect of social adjustment, it is important to work on achieving the individual's acceptance of the changes that have occurred.

\begin{tabular}{|l|l|l|l|}
\hline $\begin{array}{l}\text { Item of the } \\
\text { Question }\end{array}$ & Facet Evaluated & $\mathbf{r}$ & $\mathbf{p}$ \\
\hline 13 & Interpersonal relations & -0.73 & $<0.0001$ \\
\hline 14 & Social support & 0.79 & $<0.0001$ \\
\hline 15 & Sexual activity & -0.72 & $<0.0001$ \\
\hline
\end{tabular}

Table 5: Correlation of each question of the questionnaire to the average score for the Social Relations Domain. Participants with intestinal stoma due to colorectal cancer. Brasília, Federal District, Brazil, 2011.

Table 5 points out the facets with greater degrees of correlation to the average score registered for the Social Relations domain were interpersonal relations, sexual activity and social support, with the first two exercising a negative effect on quality of life's perceptions in this domain.

The surgical construction of a stoma affects greatly interpersonal relations. In addition to the usual problems, there are social embarrassments associated to the possibility of expelling gases and eliminating feces over which they have no voluntary control and eventual security and quality failures in the installed equipment which make them fearful of exposing themselves in public [7,9,26,31]. It is obvious that stoma patients' social relations are jeopardized and there are inaccuracies related to the importance of social support that begins with the family and can contribute towards achieving a better performance in this field of interpersonal relations.

An intestinal stoma following colorectal cancer has significant social consequences for the body, capable depriving it of integrity, dynamism and autonomy thereby causing interior conflicts and unbalance and sometimes transforming the person's relations with the external world. That includes the possibility of living out their own sexuality and their sexual activity so that it strongly affects their quality of life $[4,5,9]$.

Both man and women have their quality of life affected for the presence of a stoma. The women are more sensitive to any change in their body image, what implies in the possibility to have parts of their bodies exteriorized and the stigma associated to a person with a stoma. 
Page 6 of 7

For men, the prejudice is linked to their sexual life and they are usually under greater pressure regarding to their sexual performances [31].

The social support facet clearly revealed how important it is and the family represents the initial support. Studies suggest that a social support network is highly important for people with stomas $[4,5,31,32]$. Independent of the family structure, this unit plays an essential role in people's lives and symbolizes an important resource for facing critical situations such as a member's sickness. Families tend to support members in vulnerable situations and need help. In the case of people with stomas the family is an indispensable resource to provide the social support they need [4].

The family can offer useful information for health team, and information can be the basis for an individualized or collective health care plans. Social support is indispensable and highly meaningful in the rehabilitation process of a person with a stoma. It orientates the decisions regarding the disease, treatment, and the needed support.

\begin{tabular}{|l|l|l|l|}
\hline $\begin{array}{l}\text { Item of the } \\
\text { Question. }\end{array}$ & Facet Evaluated & $\mathbf{r}$ & $\mathbf{p}$ \\
\hline 16 & Physical safety and protection & 0.42 & 0.007 \\
\hline 17 & Home environment & 0.44 & 0.010 \\
\hline 18 & Financial situation & 0.22 & 0.004 \\
\hline 19 & $\begin{array}{l}\text { Social and health care: availability and } \\
\text { quality }\end{array}$ & -0.73 & $<0.0001$ \\
\hline 20 & $\begin{array}{l}\text { Opportunities to acquire new information and } \\
\text { skills }\end{array}$ & -0.72 & $<0.0001$ \\
\hline 21 & $\begin{array}{l}\text { Leisure/ Recreation participation and } \\
\text { opportunities }\end{array}$ & 0.38 & 0.006 \\
\hline 22 & $\begin{array}{l}\text { Physical environment: (pollution/noise/traffic/ } \\
\text { climate) }\end{array}$ & 0.29 & 0.003 \\
\hline 23 & Transport & 0.36 & 0.005 \\
\hline
\end{tabular}

Table 6: Correlation of each question of the questionnaire to the average score for the Environment Domain. Participants with intestinal stoma due to colorectal cancer. Brasília, Federal District, Brazil, 2011.

Finally, the results presented in Table 6 express the Environment domain, the correlation values were far weaker compared to those for the other domains. A previous study encountered the same result which reported weak correlation among the facets and found that even though all of them belong to the same domain, they are not necessarily closely related to one another [19].

In the case of the Environment domain, the facets with some degree of correlation were health and social care, availability and quality, and the opportunity to acquire new information and skills. It means that health services organized with focus on integrality tend to be more effective to respond demand from users and their families. There is an urgent need to institutionalize integrality practices accompanied by permanent education, especially for nursing staff because they spend a lot of time along the patients and have a tradition to deliver a holistic care [33]. The kind of care has his basis on emancipating principles; exercise of autonomy and solidarity, and on the recognition of the citizen's freedom of choice related to health care received or obtained.
The multidisciplinary health team members need to consider the subjective aspects related to social representation emerging from the person's new life style. It means that a person is a historical, social and political subject in articulation with the family and social context, as well as the surroundings where he or she lives. Another important question is the implementation of health education with the objective to construct a collective knowledge contributing to the individual's empowerment [33].

The surgical stoma for the treatment of a pre-existent neoplasm leads to a significant alteration to the physical body, introduces personal suffering and imposes the adoption of a new lifestyle. These modifications affect physical and psychological aspects, as well as the individuals' social relationships and its insertion in the ambiance. This new scenery influences the perception related to quality of life in different dimensions and facets.

Certainly, the knowledge produced by this study is important to subsidize the elaboration of holistic public policies, the reorganization of care practices provided to health users, the construction of educational programs of health promotion and rehabilitation specifically directed to the needs of the group of people living with stomas. In addition, the evidences can contribute to strengthening the health professional capabilities contributing to promote principles of solidarity and equity, and the development of an ethical culture of the respect for the human rights.

\section{References}

1. [No authors listed] (1995) The World Health Organization Quality of Life assessment (WHOQOL): position paper from the World Health Organization. Soc Sci Med 41: 1403-1409.

2. Mahjoubi B, Mirzaei R, Azizi R, Jafarinia M, Zahedi-Shoolami L (2012) A cross-sectional survey of quality of life in colostomates: a report from Iran. Health Qual Life Outcomes 10: 136.

3. Khan N, Afaq F, Mukhtar H (2010) Lifestyle as risk factor for cancer: Evidence from human studies. Cancer Lett 293: 133-143.

4. Kimura CA, Kamada I, Guilhem D, Monteiro PS (2013). Quality of life analysis in ostomized colorectal cancer patients. J Coloproctol. (Rio J.): 216-221.

5. Fortes RC, Monteiro TMTC, Kimura CA (2012). Quality of life from oncological patients with definitive and temporary colostomy. J Coloproctol. (Rio J.): 253-259.

6. Jemal A, Bray F, Center MM, Ferlay J, Ward E, et al. (2011) Global cancer statistics. CA Cancer J Clin 61: 69-90.

7. Kimura CA, Kamada I, Fortes RC, Sadi PM (2009). Reflections for professionals of health on quality of in oncological patients with ostomies. Ciências da Saúde: 333-340.

8. Cascais AFMV, Martini JG, Almeida PJS (2007). O impacto da ostomia no processo de viver humano. Texto contexto - enferm. 16(1): 169-167.

9. Kimura, CA, Kamada I, Guilhem D, Fortes RC (2013). Perception of sexual activities and the care process in ostomized women. J Coloproctol. (Rio J.): 145-150.

10. Dabirian A, Yaghmaei F, Rassouli M, Tafreshi MZ (2010) Quality of life in ostomy patients: a qualitative study. Patient Prefer Adherence 5: 1-5.

11. Violin MR, Sales CA (2010). Experiancia cotidianas de pessoas colostomizadas por cancer: enfoque existencial. Rev. Eletr. Enf. [Internet]. 12(2): 278-286.

12. [No authors listed] (1998) The World Health Organization Quality of Life Assessment (WHOQOL): development and general psychometric properties. Soc Sci Med 46: 1569-1585.

13. Brazil. Ministry of Heatlh. Nationald Health Council. (2012) Resolution N.466/2012. Guidelines and regulatory norms for research involving human subjects. Brasilia: CNS; 2012 
Citation: Kimura CA, Kamada I, de Jesus CAC, Guilhem D (2014) Quality of Life of Colorectal Cancer Patients with Intestinal Stomas . J Carcinog Mutagen S10: 007. doi:10.4172/2157-2518.S10-007

Page 7 of 7

14. Fleck MP, Louzada S, Xavier M, Chachamovich E, Vieira G, et al. (2000) [Application of the Portuguese version of the abbreviated instrument of quality life WHOQOL-bref]. Rev Saude Publica 34: 178-183.

15. Brasil. Ministario da Saade. Secretaria de Vigilancia Saade. Instituto Nacional do Cancer. Estimativas 2012: incidencia de cancer no Brasil. Rio de Janeiro: INCA.

16. Saad M, Nasri F (2008). Grupos de religiosidade e espiritualidade. In: E Knobel (Org.). Psicologia e Humanizaa: Assistncia a pacientes graves. So Paulo: Atheneu: 349-359.

17. Mohler MJ, Coons SJ, Hornbrook MC, Herinton LJ, Wendel CS, et al. (2008). The health-related quality of life in long-term colorectal cancer survivors study: objectives, methods, and patient sample. Curr Med Res Opin 24(7): 2059-2070.

18. Schneider EC, Malin JL, Kahn KL, Ko CY, Adams J, et al. (2007) Surviving colorectal cancer : patient-reported symptoms 4 years after diagnosis. Cancer 110: 2075-2082.

19. Michelone Ade P, Santos VL (2004) [Quality of life of cancer patients with and without an ostomy]. Rev Lat Am Enfermagem 12: 875-883.

20. Kaufman G, Taniguchi H (2006). Gender and marital happiness in later life. J Fam Issues 27(1): 735-757.

21. Hawkins D, Booth A (2005). Unhappily ever after: affects of long-term, low quality marriages on well-being. Social Forces 84(1): 451-475.

22. Seow A, Yuan JM, Koh WP, Lee HP, Yu MC (2006) Diabetes mellitus and risk of colorectal cancer in the Singapore Chinese Health Study. J Natl Cancer Inst 98: 135-138.

23. Chang CK, Ulrich CM (2003) Hyperinsulinaemia and hyperglycaemia: possible risk factors of colorectal cancer among diabetic patients. Diabetologia 46: 595-607.

24. Sturmer T, Glynn RJ, Lee IM, Christen WC, Hennekens CH (2000). Lifetime cigarette smoking and colorectal cancer incidence in the Physicians Health Study. J. Natl. Cancer Inst. 92(14): 1178-1181.
25. Martins PA, Alvim NA (2011) [Educational perspective on nursing care about the maintenance of elimination ostomy]. Rev Bras Enferm 64: 322-327.

26. Stumm NMF, Oliveira ERA, Kirschner RM (2008). Perfil de pacientes ostomizados. Soc Sci Med 18(1): 26-30.

27. Ramirez M, McMullen C, Grant M, Altschuler A, Hornbrook MC, et al. (2009) Figuring out sex in a reconfigured body: experiences of female colorectal cancer survivors with ostomies. Women Health 49: 608-624.

28. Li Chun C, Rew L, Hwang S (2012). The relationship between spiritual well-being and psychosocial adjustment in Taiwanese patients with colorectal cancer and a colstoma. J Wound Stoma Continence Nurs. 39(2): 161-169.

29. Barbutti RCS, Silva MCP, Abreu MAL (2008). Ostomia, uma difícil adaptação. Rev. SBPH 11(2): 27-39.

30. Almeida SSL, Rezende AM, Schall VT, Modena CM (2010). Os sentidos da corporeidade em ostomizados por cancer. Revista Paraná 15(4): 761-769..

31. Baldwin CM, Grant M, Wendel C, Hornbrook MC, Herrinton LJ, et al. (2009) Gender differences in sleep disruption and fatigue on quality of life among persons with ostomies. J Clin Sleep Med 5: 335-343.

32. da Silva AL, Shimizu HE (2007) [The importance of the Support Network for the stomized patient]. Rev Bras Enferm 60: 307-311.

33. Pinto IC, Marciliano CS, Zacharias FC, Stina AP, Passeri IA, et al. (2012) Nursing care practices at an outpatient care center from an integrative perspective. Rev Lat Am Enfermagem 20: 909-916. 